\title{
Body wave dispersion characteristics of regional deep earthquake at Southern Ryukyus subduction zone
}

\author{
Haekal A. Haridhi ${ }^{1,2,3,{ }^{*}, \text { Bor-Shouh Huang }}{ }^{4}$, Dimas Sianipar ${ }^{5}$, Syahrul Purnawan ${ }^{1,2}$, Ichsan Setiawan $^{1,2}$ \\ ${ }^{1}$ Department of Marine Sciences, Faculty of Marine and Fisheries, Universitas Syiah Kuala, Banda Aceh 23111, Indonesia. \\ ${ }^{2}$ Tsunami and Disaster Mitigation Research Center (TDMRC), Universitas Syiah Kuala, Banda Aceh 23111, Indonesia. \\ ${ }^{3}$ Research Center for Marine Sciences and Fisheries, Universitas Syiah Kuala, Banda Aceh 23111, Indonesia. \\ ${ }^{4}$ Institute of Earth Science, Academia Sinica, Taipei 115, Taiwan. \\ ${ }^{5}$ Agency for Meteorology, Climatology, and Geophysics (BMKG), Jakarta 10610, Indonesia.
}

\begin{abstract}
The convergent plate boundaries known as the subduction zone is the location where the cold, hydrate, and old oceanic plate subduct under the hot, dry, and young continental plate. The top of the oceanic plate, i.e. the oceanic crust usually is less than $6 \mathrm{~km}$ thick carries the hydrate material to the hot continental mantle, which is commonly an indication of the occurrence of the deep earthquake. From the recent studies, the deep regional earthquake body wave signal that occurred at the subduction zone was found dispersed and or shown as a waveguide. Thus, by examining these signals, we could further estimate the body wave characteristics at the subduction zone. A narrow bandpass signal and the maximum of Hilbert transform envelope are being used to estimate the delay time of the dominant frequency energy at the Southern Ryukyus subduction zone. It was found that the Southern Ryukyus has a larger delay with the dominant frequency at $2 \mathrm{~Hz}$, thus, the signal travel within the oceanic crust where it acts as a low-velocity layer compared to the surrounding continental and oceanic mantle, inversely it is known as a high-quality material (preserve the high-frequency energy).
\end{abstract}

\section{Introduction}

Taiwan is considered the most actives tectonic region. Its geographical location emerges between two distinct convergent systems of the Eurasian and Philippine Sea Plates, where at southern Taiwan the Eurasian Plate plunge under the Philippine Sea Plate while opposing to that situation occurred at its northern [1]. With support from the Ministry of Science and Technology of Taiwan, in recent years, The Institute of Earth Sciences of the Academia Sinica and the Tatun Volcano Observatory deployed a new high-density broadband seismic station at the northern Taiwan area named as Formosa Array (FM Array), with a total of 140 stations being constructed [2]. These seismic stations were aimed to understand the geometry of the magma chamber beneath the Tatun volcanic area, however, we could also utilize them to study the properties of the subducting slab.

One important observation applied to the intermediate-deep earthquake is the body wave dispersion. The body wave dispersion study has recently been used as a tool to estimate the properties of the subducting plate [3-5].

Understanding the subducting plate properties is essential, not only could explain the occurrence of the intermediate-deep seismicity, but also could be used to estimate its effect on ground motion. The study of the 1909 Taipei earthquake particularly indicates the importance to assess the shaking hazard resulting from an intermediate-deep earthquake [6] which is usually underestimated, such as the study of the Inishkin 2016 Mw 7.1 at $111 \mathrm{~km}$ depth, Alaska earthquake, indicates the subduction zone structure may contribute to the hazardous strong shaking at the forearc area (Anchorage and the Kenai Peninsula) of the Alaska subduction zone [7].

Therefore, studying the properties of the subducting slab, especially through the characteristics of the body wave signals from the deep regional earthquake are considered urgent and important. It may give a contribution to understanding the anomalous ground shaking distribution along the north eastern coast of Taiwan associated with deep earthquakes [8]. The finding in Taiwan resulting from this study could be applied elsewhere, along the subduction region around the world.

\section{Seismotectonic Background}

Taiwan is located between two convergent plate boundaries, where at the south of Taiwan, the subduction of the South China Sea (SCS) as part of Eurasian Plate subducted beneath the Philippine Sea Plate (PSP) along the manila trench [9]. Taiwan has been known as one of the very active tectonics activities, as a number of large earthquakes, occurred along this island due to its geologic configurations [1]. As it is

*Corresponding author: haekal.azief.haridhi@unsyiah.ac.id 
shown in Figs. 1(a), almost all regions in Taiwan experience earthquake events.

One of many recent destructive earthquakes indicate that a continuous improvement needs to be done to understand the characteristics of the ground movement and the earthquake source [10]. Not only for the shallow destructive earthquake but also the deep regional earthquake, which ever destroy most of the buildings in Taipei, in the northern Taiwan region, and its deemed important to study the characteristics of the regional deep earthquakes, especially with the high density of population [6].

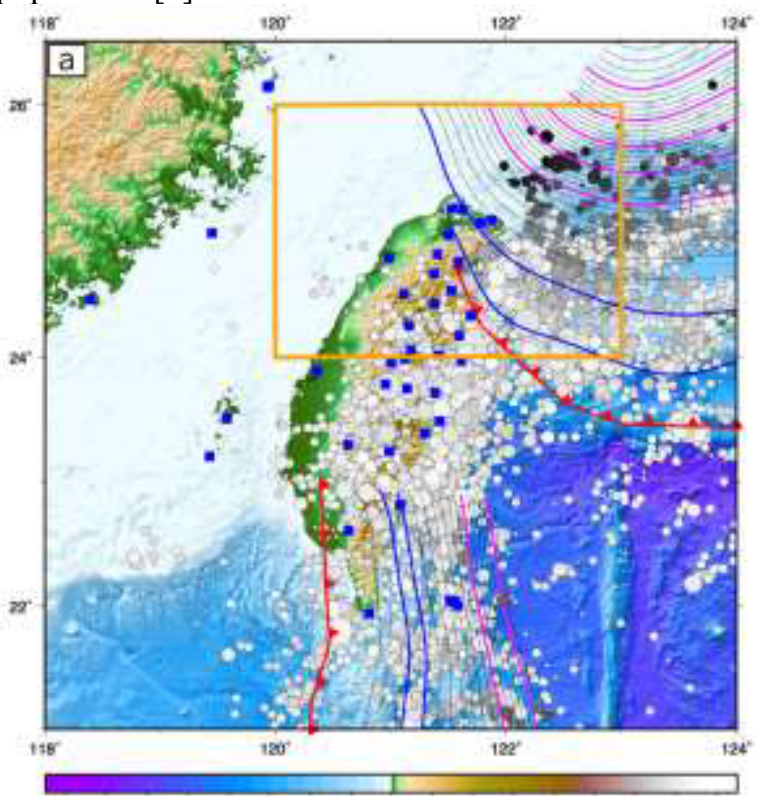

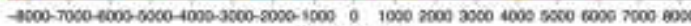

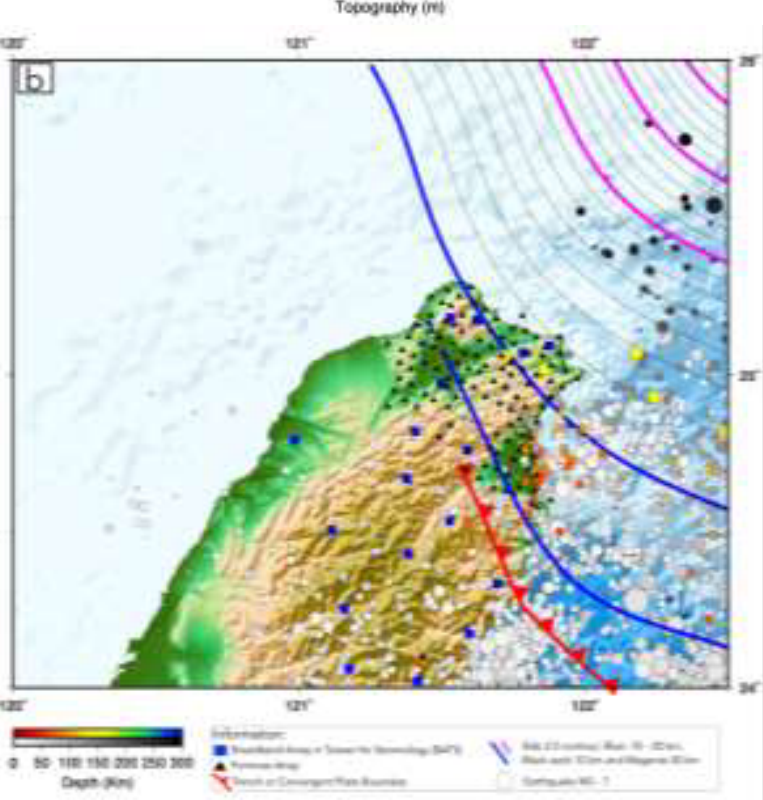

Fig. 1. (a) The topographic map of Taiwan showed the distribution of seismicity along the convergent plate boundary between Eurasian and Philippine Sea Plates in the south and the north. The distinct plate boundaries at the south and north called the Manila and Ryukyu trenches showed as a thick red line with tooth representing their locations, respectively. The distribution of broadband seismic stations, known as Broadband Array in Taiwan for Seismology (BATS) covered the whole island and its outskirt, is shown as a blue square and the study location is shown by the orange rectangle at northern Taiwan region shown in (b). (b) The northern Taiwan region with the location of Formosa Array (FM Array) seismic stations is shown as a black triangle. The grayscale colored circles indicate the earthquake event retrieved from the ISC earthquake catalogue (http://www.isc.ac.uk/), while the hot colored circle indicates the intermediate - deep regional events analyzed in this study. Slab 2.0 [11] contour is shown by different colors indicate different depths as it is shown in the information.

The Regional deep earthquake in northern Taiwan has been known to produce an anomalous ground movement distributed at the east - north coast of Taiwan [8]. The presence of the subducting slab is considered as the major factor in contributing to the enhanced ground movement, where such observation is true along the Alaska subduction zone [7]. However, northern Taiwan region due to its complicated tectonics, the north eastern region, which is located at the edge of the Ryukyu subduction, hence it is difficult to quantify the slab contribution to the ground movement. Thus, in recent year, the Institute of Earth Science, Academia Sinica, and the Tatun Volcano Observatory has been installed a high-density seismic station in the northern Taiwan region called as Formosa Array (FM Array), as is shown in Fig. 1 (b) [2]. Had the advantage of high seismic stations density, the characteristic of the slab estimated by the regional deep events could be assessed.

\section{Material and Method}

\subsection{Regional deep earthquake catalogue}

The regional deep earthquakes data that we analyse in this study are listed in Table 1.

Table 1. The Taiwan Central Weather Bureau intermediatedeep (60 - $152 \mathrm{~km}$ depth) earthquake catalogue during 2018

-2019 located at the north - north eastern Taiwan with magnitude between $3-5$. DT: date time, LON: longitude, LAT: latitude, M: magnitude, Z: depth in $\mathrm{km}$.

\begin{tabular}{|c|c|c|c|c|c|}
\hline No & DT & LON & LAT & M & $\mathbf{Z}$ \\
\hline 1 & $\begin{array}{c}2018 / 01 / 17 \\
13: 59: 11.11\end{array}$ & 121.72 & 25.06 & 5.5 & 140.2 \\
\hline 2 & $\begin{array}{c}2018 / 03 / 01 \\
21: 42: 26.26\end{array}$ & 123.92 & 24.42 & 5.8 & 68.3 \\
\hline 3 & $\begin{array}{c}2018 / 03 / 06 \\
17: 42: 10.10\end{array}$ & 121.86 & 24.7 & 4.9 & 81.7 \\
\hline 4 & $\begin{array}{l}2018 / 03 / 28 \\
18: 29: 58.58\end{array}$ & 121.98 & 24.65 & 4.9 & 63.7 \\
\hline 5 & $\begin{array}{l}2018 / 04 / 20 \\
13: 25: 06.06\end{array}$ & 122.37 & 24.37 & 4.7 & 70.6 \\
\hline 6 & $\begin{array}{c}2018 / 05 / 13 \\
05: 18: 44.44\end{array}$ & 121.95 & 24.73 & 4.3 & 78.8 \\
\hline 7 & $\begin{array}{l}2018 / 06 / 02 \\
19: 25: 15.15\end{array}$ & 121.91 & 24.5 & 4.2 & 60.4 \\
\hline
\end{tabular}




\begin{tabular}{|c|c|c|c|c|c|}
\hline 8 & $\begin{array}{c}2018 / 06 / 18 \\
23: 06: 15.15\end{array}$ & 122.63 & 24.81 & 4.7 & 126.4 \\
\hline 9 & $\begin{array}{l}2018 / 06 / 16 \\
09: 08: 58.58\end{array}$ & 121.83 & 24.68 & 3.8 & 63.2 \\
\hline 10 & $\begin{array}{l}2018 / 06 / 16 \\
04: 53: 56.56\end{array}$ & 121.84 & 24.67 & 5.3 & 63.2 \\
\hline 11 & $\begin{array}{l}2018 / 06 / 26 \\
03: 07: 31.31\end{array}$ & 122.06 & 24.75 & 4.1 & 68.2 \\
\hline 12 & $\begin{array}{l}2018 / 07 / 14 \\
19: 46: 07.07\end{array}$ & 121.8 & 24.56 & 4.3 & 67.4 \\
\hline 13 & $\begin{array}{c}2018 / 07 / 20 \\
09: 39: 15.15\end{array}$ & 121.51 & 20.78 & 5.6 & 99.8 \\
\hline 14 & $\begin{array}{l}2018 / 08 / 04 \\
09: 49: 20.20\end{array}$ & 121.79 & 24.66 & 4.1 & 76.4 \\
\hline 15 & $\begin{array}{l}2018 / 08 / 06 \\
05: 30: 22.22\end{array}$ & 122.65 & 24.6 & 4.6 & 97.4 \\
\hline 16 & $\begin{array}{l}2018 / 08 / 09 \\
16: 01: 32.32\end{array}$ & 120.18 & 20.99 & 4.9 & 86.2 \\
\hline 17 & $\begin{array}{l}2018 / 08 / 11 \\
10: 24: 20.20\end{array}$ & 121.55 & 22.31 & 4.2 & 116.2 \\
\hline 18 & $\begin{array}{l}2018 / 08 / 31 \\
04: 14: 24.24\end{array}$ & 122.31 & 24.72 & 4.6 & 100.5 \\
\hline 19 & $\begin{array}{c}2018 / 09 / 04 \\
00: 37: 10.10\end{array}$ & 121.99 & 24.83 & 4.3 & 89.8 \\
\hline 20 & $\begin{array}{l}2018 / 10 / 21 \\
07: 10: 42.42\end{array}$ & 121.41 & 24.08 & 4.3 & 63 \\
\hline 21 & $\begin{array}{c}2018 / 11 / 03 \\
03: 23: 54.54\end{array}$ & 121.73 & 24.58 & 3.7 & 64.4 \\
\hline 22 & $\begin{array}{l}2018 / 11 / 09 \\
14: 59: 17.17\end{array}$ & 121.93 & 24.76 & 3.9 & 87.2 \\
\hline 23 & $\begin{array}{l}2018 / 11 / 16 \\
10: 01: 35.35\end{array}$ & 121.81 & 24.79 & 4.4 & 82.3 \\
\hline 24 & $\begin{array}{l}2018 / 11 / 16 \\
08: 34: 19.19\end{array}$ & 122.69 & 24.31 & 4.9 & 69.1 \\
\hline 25 & $\begin{array}{l}2018 / 11 / 27 \\
19: 25: 49.49\end{array}$ & 121.83 & 24.7 & 4 & 83.6 \\
\hline 26 & $\begin{array}{c}2019 / 01 / 02 \\
20: 27: 21.21\end{array}$ & 121.91 & 24.72 & 3.9 & 80.1 \\
\hline 27 & $\begin{array}{c}\text { 2019/03/06 } \\
09: 33: 29.29\end{array}$ & 121.79 & 24.76 & 4.1 & 86.7 \\
\hline 28 & $\begin{array}{l}2019 / 03 / 13 \\
04: 19: 15.15\end{array}$ & 121.86 & 25.02 & 5.3 & 138 \\
\hline
\end{tabular}

\begin{tabular}{|c|c|c|c|c|c|}
\hline 29 & $\begin{array}{l}2019 / 03 / 19 \\
12: 01: 34.34\end{array}$ & 121.93 & 24.75 & 4.9 & 83.2 \\
\hline 30 & $\begin{array}{l}2019 / 03 / 22 \\
20: 05: 48.48\end{array}$ & 122.45 & 24.49 & 4.9 & 88.8 \\
\hline 31 & $\begin{array}{c}2019 / 03 / 24 \\
15: 56: 50.50\end{array}$ & 122.43 & 24.7 & 4.7 & 109.3 \\
\hline 32 & $\begin{array}{l}2019 / 03 / 31 \\
00: 07: 08.08\end{array}$ & 121.59 & 24.53 & 4 & 66.3 \\
\hline 33 & $\begin{array}{l}2019 / 04 / 01 \\
10: 54: 35.35\end{array}$ & 122.24 & 24.93 & 5.1 & 128.6 \\
\hline 34 & $\begin{array}{l}2019 / 04 / 07 \\
02: 22: 56.56\end{array}$ & 121.6 & 24.66 & 3.8 & 60.5 \\
\hline 35 & $\begin{array}{l}2019 / 05 / 08 \\
23: 48: 47.47\end{array}$ & 122.49 & 24.82 & 5.1 & 122.7 \\
\hline 36 & $\begin{array}{l}2019 / 05 / 03 \\
05: 47: 43.43\end{array}$ & 121.91 & 24.83 & 4.3 & 101.1 \\
\hline 37 & $\begin{array}{c}2019 / 05 / 16 \\
12: 16: 34.34\end{array}$ & 121.56 & 24.67 & 3.8 & 60.7 \\
\hline 38 & $\begin{array}{c}2019 / 06 / 02 \\
15: 51: 23.23\end{array}$ & 121.94 & 24.71 & 4.2 & 64.9 \\
\hline 39 & $\begin{array}{l}2019 / 06 / 30 \\
00: 20: 06.06\end{array}$ & 122.18 & 25.07 & 5 & 152.1 \\
\hline 40 & $\begin{array}{l}2019 / 07 / 16 \\
19: 12: 30.30\end{array}$ & 122.43 & 24.22 & 4.7 & 64.2 \\
\hline 41 & $\begin{array}{l}2019 / 07 / 26 \\
14: 39: 57.57\end{array}$ & 121.84 & 24.75 & 4.7 & 62.7 \\
\hline 42 & $\begin{array}{l}2019 / 08 / 08 \\
07: 02: 22.22\end{array}$ & 121.82 & 24.61 & 4.6 & 68 \\
\hline 43 & $\begin{array}{l}2019 / 09 / 19 \\
22: 50: 21.21\end{array}$ & 121.8 & 24.78 & 3.9 & 80.5 \\
\hline 44 & $\begin{array}{l}2019 / 10 / 13 \\
13: 20: 50.50\end{array}$ & 122.01 & 24.8 & 3.9 & 86.6 \\
\hline 45 & $\begin{array}{l}2019 / 11 / 09 \\
07: 47: 05.05\end{array}$ & 121.83 & 24.81 & 3.7 & 83.3 \\
\hline 46 & $\begin{array}{l}2019 / 11 / 12 \\
02: 11: 33.33\end{array}$ & 121.92 & 24.88 & 4.5 & 109 \\
\hline 47 & $\begin{array}{l}\text { 2019/12/07 } \\
03: 32: 33.33\end{array}$ & 122.66 & 24.54 & 4.7 & 100.5 \\
\hline
\end{tabular}

\subsection{Method}

To study the body wave dispersion, the continuous record signals from FM Array were cut based on the catalogue shown in Table 2. The seismogram then processed to remove its instrument response by using 
the transfer function in the Seismic Analysis Code (SAC) $[12,13]$ to displacement.

The horizontal components of the East-West and North-South, were then rotated to Great Circle Path (GCP) as the Radial and Transverse components. Then manual picking of $\mathrm{P}$ - and S-wave throughout all events are performed. After the picking, 10 seconds signal with 5 seconds before and after P- and S-wave arrivals were cut. A tapper of 0.05 was applied at both end of the 10 second signals. A narrow bandpass of $0.25 \mathrm{~Hz}$ is applied to the seismogram until its corner frequency, then Hilbert transform was performed. The peak amplitude of the Hilbert transforms envelope function for each narrow bandpass signal was then used to calculate the lag time relative to the manual pick and $0.25 \mathrm{~Hz}$.

The narrow band signal, is following this form $\exp \{-$ $\mathrm{a}$ (f-fi)2/fin) $\}$, where fi are the narrow band frequency, a and $\mathrm{n}$ is constant. Following this procedure, it gives a smooth dispersion curve. This approach are intensively being used to estimate the body wave dispersion curve at the subduction zone around the world $[3-5,14]$ and it is similar to that being used in measuring the surfacewave group velocity [15].

\section{Result}

\subsection{Waveform characteristics}

The characteristics of the body wave that travel within the subducting slab have distinctive characteristics. The body wave arrival showed a small amplitude onset, and a large amplitude arrived soon after the onset with a couple of milliseconds intermittent between them, which is known as a waveguide (focused energy) or dispersed signals. Figs. $2 \mathrm{a}-\mathrm{b}$ and $\mathrm{c}-\mathrm{d}$ indicate a waveform characteristic of a station that records the signal that does travel within the slab and with the one that did not.

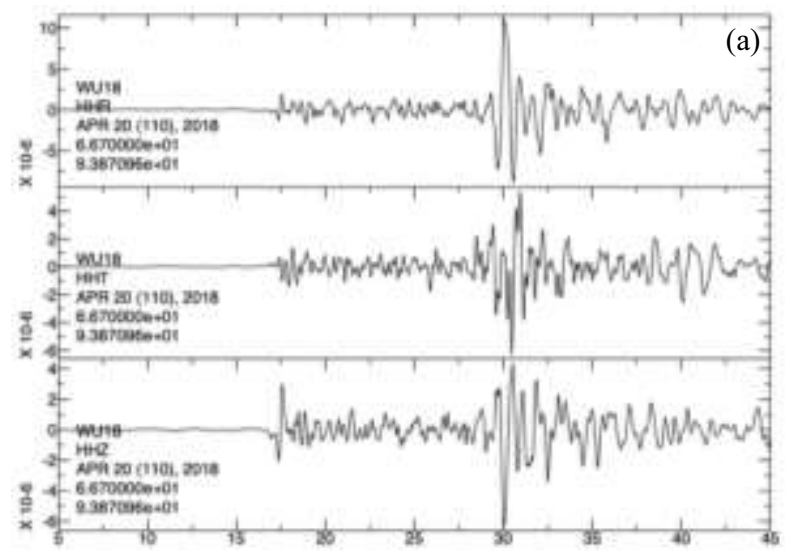

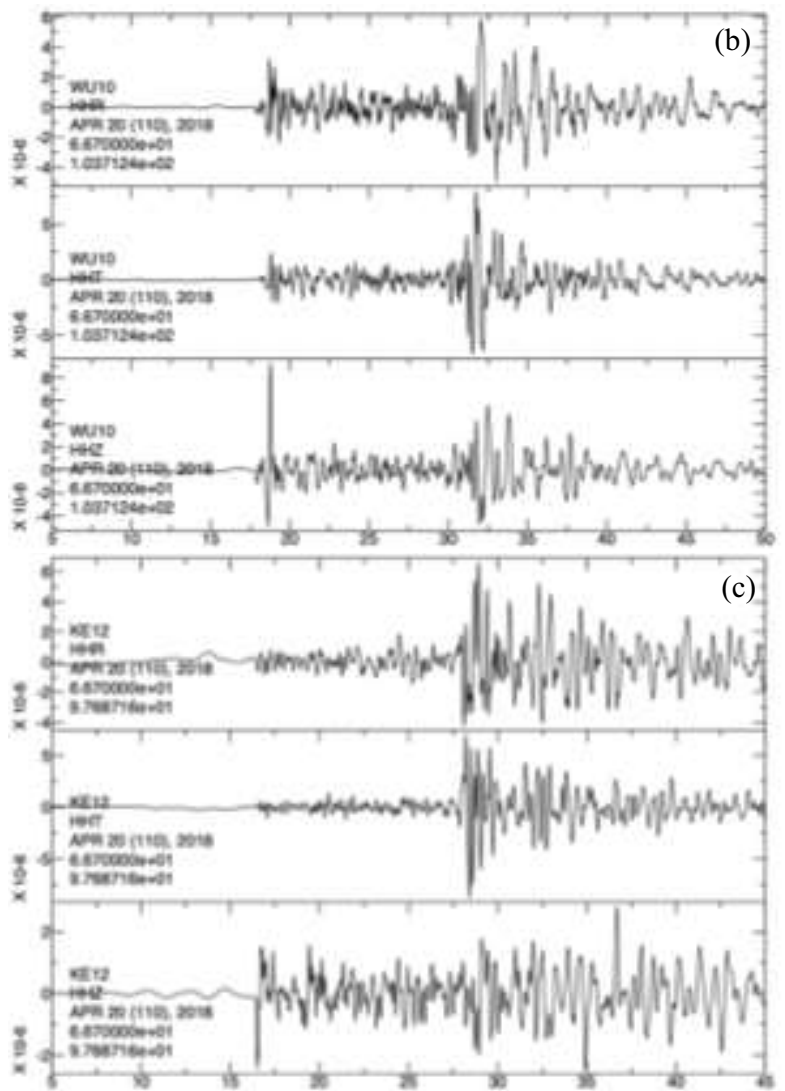

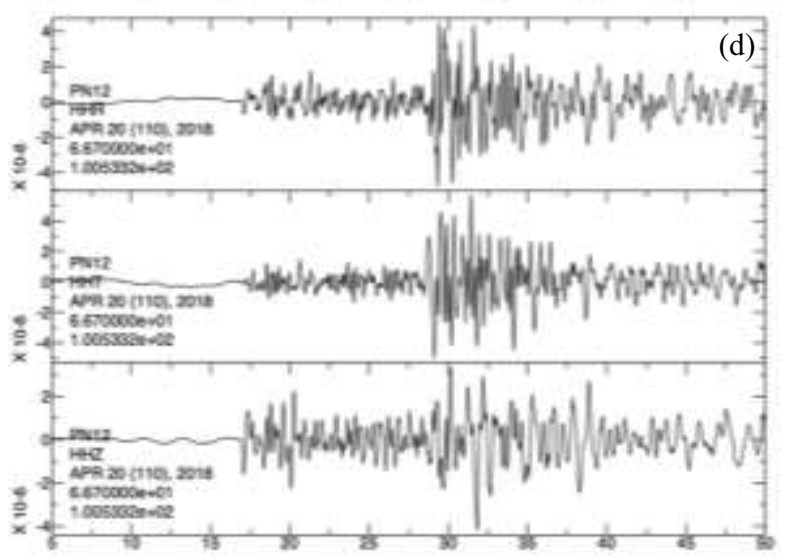

Fig. 2. Seismogram records of 4 stations with a similar distance between one and another, that showed a distinctive characteristic of P- and S-wave arrivals. (a) and (b): nonimpulsive arrival of P-wave on HHZ component as well as for the S-Wave on HHT component, thus sampled the slab (waveguide). (c) and (d): impulsive arrival of P-wave on HHZ component as well as for the S-wave on HHT, thus nonsampled the slab (non-waveguide).

The waveguide or dispersed signal is observed only at the station that sampled the slab, which means the seismic wave trapped within a lower velocity medium to its surroundings which is able to trap the energy.

Differ to the non-guided signal which has the dominant frequency mostly depends on the soil type on the receiver or stations, i.e. soil or rock sites, the guided signal has its dominant frequency depending on the thickness of the low-velocity layer, appropriately within a certain range of frequency which depends on the thickness the layer, i.e. the subducted oceanic crust. 


\subsection{Body wave arrival time characteristics}

The characteristics of the dispersed body wave at northern Taiwan, the southern Ryukyus subduction zone observed delayed at some particular station locations, especially the stations that located between $10-20 \mathrm{~km}$ from the subducted slab interface. For example, Figs. 3a showed an event located at a depth of $66.7 \mathrm{~km}$ with $\mathrm{M}$ 4.7 on 20 April 2018 (the same event shown in Figs. 2 a-d). The WU18 stations showed a distinctive delay in $\mathrm{P}$-wave arrivals compared to the other recording stations (Figs. 3b).

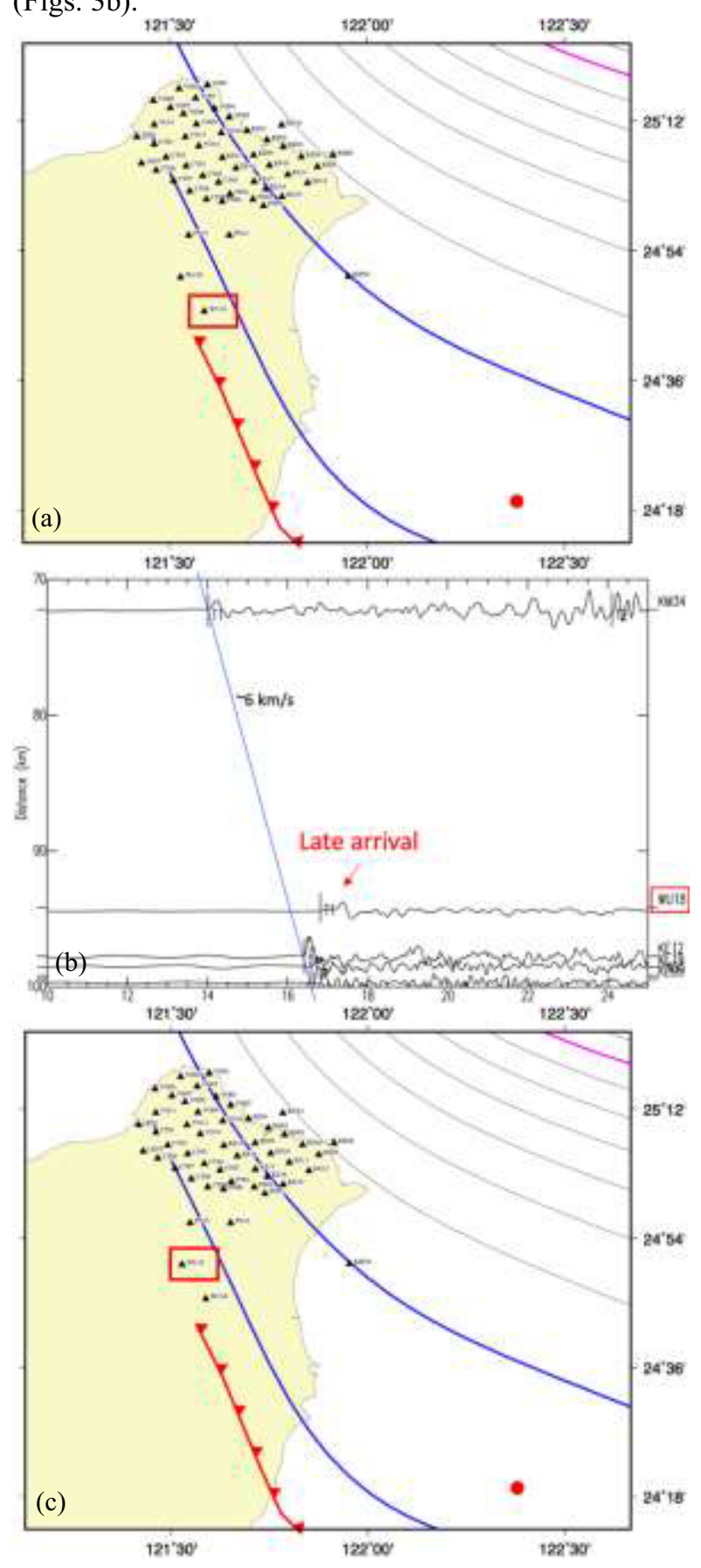

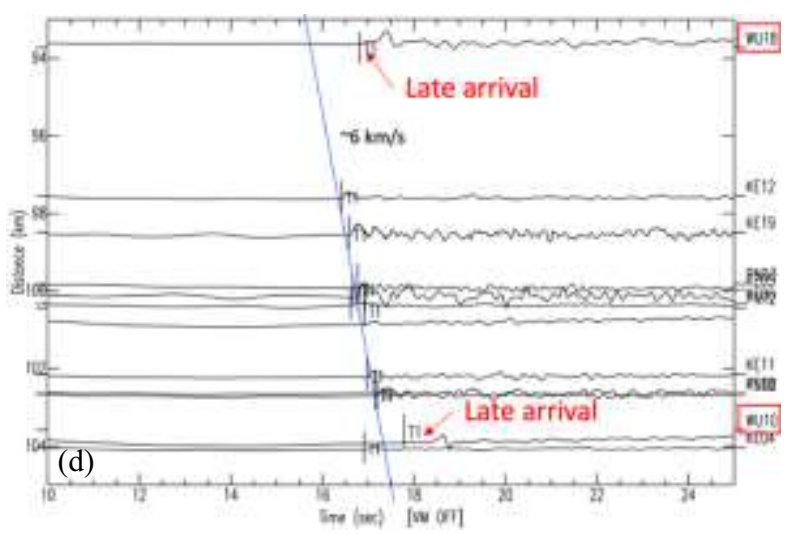

Fig. 3. (a) and (c) The northern Taiwan region and southern Ryukyus subduction zone. The land is shown as a cream color and the location of FM Array stations is shown by black triangle with text indicating its station name. The trench is indicated by the red toothy lines, and its interface contoured for each $10 \mathrm{~km}$ depth, with $10-20 \mathrm{~km}$ depth colored in blue, $100 \mathrm{~km}$ depth colored in magenta, while the rest colored in a thin solid black line. The event of DT 20 April 2018, M 4.7, Z $66.7 \mathrm{~km}$ indicated by a red dot. The red rectangle indicates the location of WU18 and WU10 seismic stations for (a) and (c), respectively. (b) and (d) The Signal Stacking Subprocesses (SSS) with an apparent velocity normal moveout (VNMO) of $6 \mathrm{~km} / \mathrm{s}$ shown as the solid blue line. The WU18 and WU10 seismic stations indicated an obvious delay compared to the other recording stations.

As it is shown in Figs. 3 a-d, the arrival of P- and Swave were delayed only at the stations that located $10-$ $20 \mathrm{~km}$ above the slab interface. The delayed usually correspond positively with the depth of event, where a larger delay being observed at a deeper event.

\subsection{Spectrogram characteristic}

The spectrogram characteristics of the waveguide or dispersed signals indicate that the signal recorded at the station $10-20 \mathrm{~km}$ above the slab interface displays enriched high-frequency amplitudes. The arrival of each frequency energy showed a delay of high-frequency signal about $1.5-2$ seconds, as is shown in Figs. 4 a and b. Focusing on high-frequency energy was one of the characteristics of a waveguide. On the other hand, the non-sampled slab stations showed no delay between the low-high frequency on the spectrogram, as it is shown in Figs. $4 \mathrm{c}$ and $\mathrm{d}$.

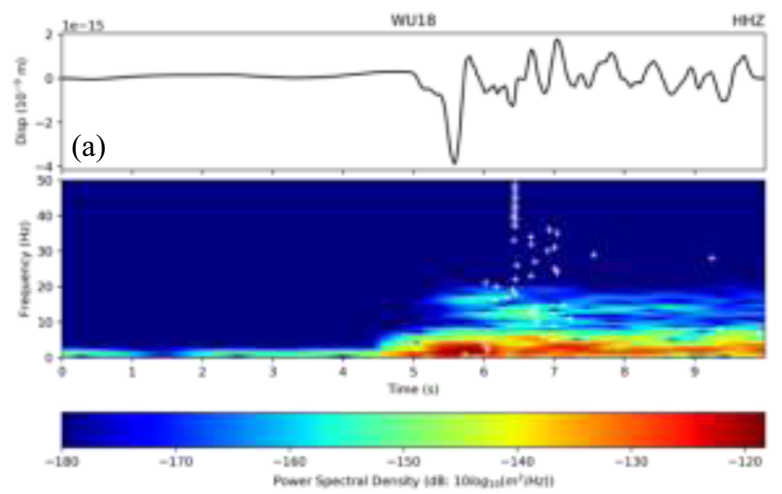



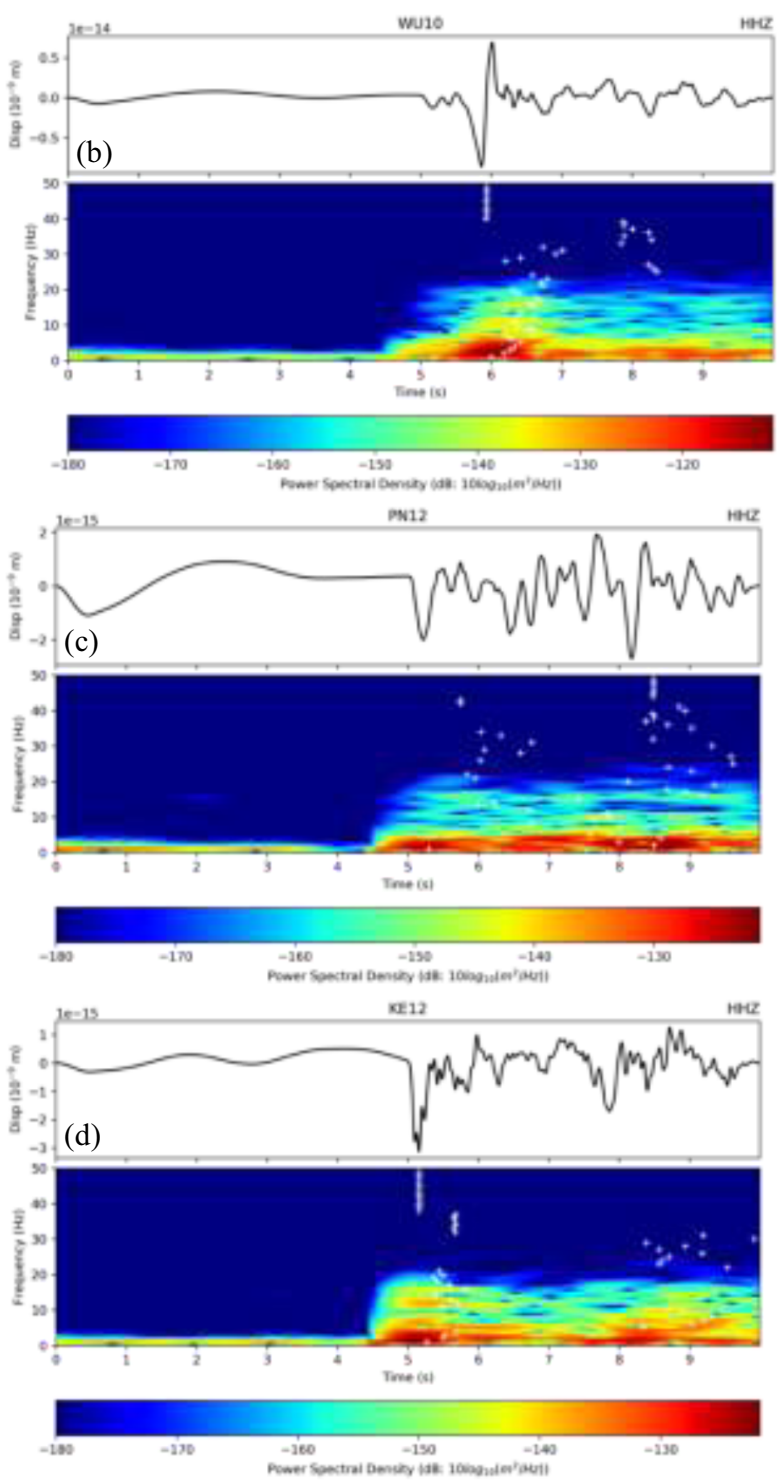

Fig. 4. The 10 seconds seismogram (P-wave are set at 5 second) and its corresponding spectrogram of the same event shown in Figs. 2 a-d. (a) and (b) A typical wave guide or dispersed body wave. (c) and (d) A typical non-wave guide or a typical body wave.

\section{Conclusion}

The characteristics of body wave observed in the northern Taiwan region showed as a guided wave at the particular station locations, especially those located at between $10-20 \mathrm{~km}$ above the subducting plate interface. The distinct characteristics of the seismogram, $\mathrm{P}$ - and $\mathrm{S}$-wave arrival time as well as its spectrogram are distinguishable between the seismic wave that travels within the oceanic crust and the other that does not. The waveguide is recently being used as a tool to estimate the subducting slab properties, as well as a mitigation effort. The focused energy in a certain frequency has a significant effect on the building, hence a higher risk of disaster and or damage to the building should be anticipated. This observation is only possible with a dense seismic array such as the FM Array, beside the tectonic setting of the region, such that, the Indonesian subduction zone, thought, limited stations are available, this phenomenon is also observed at the forearc islands [16].

Acknowledgment: We would like to send our greatest gratitude to the Institute of Earth Sciences (IES), Academia Sinica and the Tatun Volcano Observatory (TVO) at Taipei, Taiwan for the availability FM Array dataset. The FM Array dataset is available upon request to IES and TVO. This study was supported by the Ministry of Education and Culture of the Republic of Indonesia under the Institute of Research and Community Service (LPPM) of Universitas Syiah Kuala within the H-Index Scheme (grant number 169/UN11/SPK/PNBP/2021). The Generic Mapping Tools software package was used to draw map figures [17].

\section{References}

1. Y.-B. Tsai, Tectonophysics 125, 17 (1986)

2. Academia Sinica, Institute of Earth Science, and Tatun Volcano Observatory, Int. Fed. Digit. Seismogr. Networks. Dataset/Seismic Netw. (2017)

3. G. A. Abers and G. Sarker, Geophys. Res. Lett. 23, 1171 (1996)

4. G. A. Abers, Phys. Earth Planet. Inter. 149, 7 (2005)

5. G. A. Abers, Earth Planet. Sci. Lett. 176, 323 (2000)

6. H. Kanamori, W. H. K. Lee, and K. F. Ma, Geophys. J. Int. 191, 126 (2012)

7. M. E. Mann and G. A. Abers, Seismol. Res. Lett. 91, 85 (2019)

8. K. H. Chen, B. L. N. Kennett, and T. Furumura, J. Geophys. Res. Solid Earth 118, 665 (2013)

9. C. H. Lin, B. S. Huang, and R. J. Rau, Earth Planet. Sci. Lett. 174, 231 (1999)

10. H. Kanamori, L. Ye, B. S. Huang, H. H. Huang, S. J. Lee, W. T. Liang, Y. Y. Lin, K. F. Ma, Y. M. Wu, and T. Y. Yeh, Terr. Atmos. Ocean. Sci. 28, 637 (2017)

11. G. P. Hayes, G. L. Moore, D. E. Portner, M. Hearne, H. Flamme, M. Furtney, and G. M. Smoczyk, Science (80-. ). 362, 58 (2018)

12. P. Goldstein and A. Snoke, Inc. Institutions Seismol. Data Manag. Cent. Electron. Newsl. (2005)

13. P. Goldstein, D. Dodge, M. Firpo, and L. Minner, Int. Geophys. 81, 1613 (2003)

14. T. Garth and A. Rietbrock, Earth Planet. Sci. Lett. 474, 237 (2017)

15. A. Dziewonski, S. Bloch, and M. Landisman, Bull. Seismol. Soc. Am. 59, 427 (1969)

16. H. A. Haridhi and D. Sianipar, IOP Conf. Ser. Earth Environ. Sci. 674, (2021)

17. P. Wessel and W. H. F. Smith, Eos, Trans. Am. Geophys. Union 72, 441 (1991) 